\title{
SHAKING TABLE TEST OF ADJACENT BUILDING MODELS CONSIDERING POUNDING
}

\author{
K. FUJII \& Y. SAKAI \\ Chiba Institute of Technology, Japan.
}

\begin{abstract}
Seismic pounding may cause severe structural damage to buildings, such as partial or total collapse, and/or significant damage to non-structural elements. This may be caused by the difference in the dynamic properties of each building, and also an insufficient gap between each building. In this study, a shaking table test of building models was carried out to investigate the seismic pounding of (1) low-rise buildings and (2) a low-rise to a mid-rise building. The structural specimens considered in this study were two single-storey models with a different horizontal stiffness, and one two-storey model. The test parameters were a) pairings of building models, b) the size of gaps, and c) ground acceleration records. Based on the test results, the increment of kinetic energy during the collision was evaluated. The main findings from the test results are as follows: (1) In the case of the pounding of low-rise buildings, the peak displacement of the stiffer building increases, while that of the more flexible building decreases; (2) In the case of the pounding of a low-rise building to a mid-rise building, the peak inter-storey drift of the low-rise building increases. In the mid-rise building, the peak inter-storey drift of the upper storey increases, while that of the lower storey decreases; (3) The sum of the increment kinetic energy during the collision was larger as the gap between buildings was smaller. A significant loss of kinetic energy was seen in buildings whose maximum kinetic energy is larger. (4) The building model of smaller kinetic energy may gain more energy owing to collisions, and the unfavourable effect of seismic pounding to the response is predominant.

Keywords: kinetic energy, pounding of adjacent buildings, shaking table test.
\end{abstract}

\section{INTRODUCTION}

In the downtown area of major cities, there are many buildings whose height and/or structure are different within a limited space. When the gap between adjacent buildings is insufficient, seismic pounding may occur as a result of the difference in the dynamic properties of each building. This may cause severe structural damage to buildings, such as partial or total collapse, and/or significant damage to non-structural elements. Figure 1 shows the damaged buildings possibly caused by seismic pounding during the 2016 Kumamoto Earthquake. Such damaged buildings have been observed in previous major earthquakes, such as the 1985 Mexico Earthquake [1], the 1989 Loma Prieta Earthquake [2, 3], and the 2011 Christchurch Earthquake [4].

The seismic pounding of building structures has been analytically studied by many researchers, such as Kasai [2, 3, 5], Anagonostopoulos [6, 7], Wada et al. [8], and Jankowski [9, 10]. In Wada et al. [8] and Jankowski [10], it has been found that structural pounding during an earthquake has a significant influence on the behaviour of the lighter buildings. Experimental studies of seismic pounding have also been carried out by Papadrakakis and Mouzakis [11], Chau et al. [12], and Jankowski [13]. The study by Papadrakakis and Mouzakis [11] showed that the seismic input energy of a stiffer structure increases as a result of pounding.

During seismic pounding, the kinetic energy of each structure is drastically changed during the collision period; one structure may lose while the other may gain kinetic energy. Energy dissipation also occurs as a result of the non-elastic collisions. Therefore, from the viewpoint of the authors, it is important to focus on the change in the kinetic energy of each structure during the collision to understand the phenomenon of seismic pounding. 


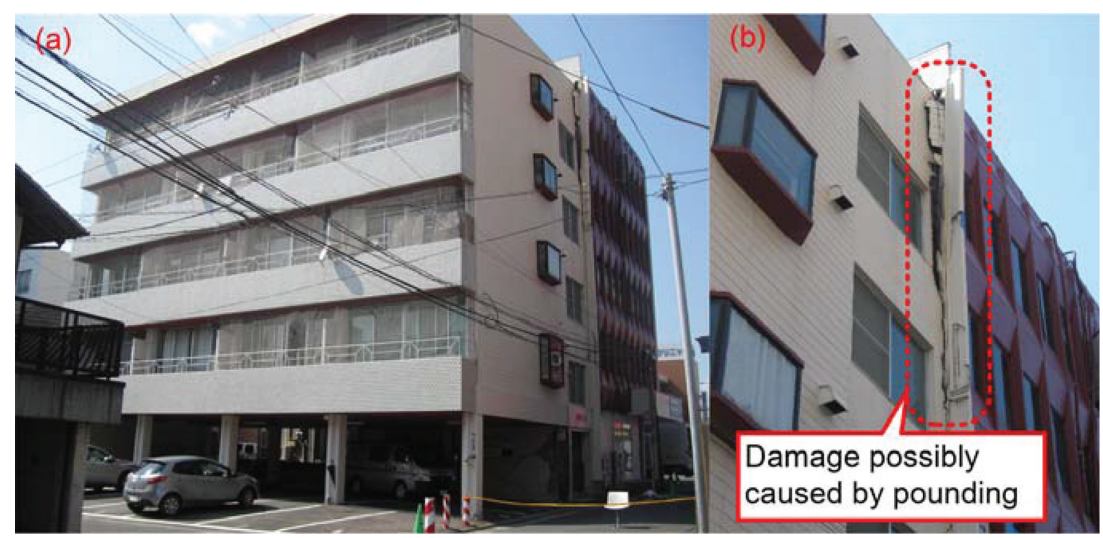

Figure 1: Damaged buildings possibly caused by the seismic pounding during the 2016 Kumamoto Earthquake. (a) Overview of the damaged buildings, and (b) a damaged non-structural element.

In this study, a shaking table test of building models was carried out to investigate the seismic pounding of (1) low-rise buildings, and (2) a low-rise building to a mid-rise building. Based on the test results, the increment of kinetic energy during collisions is evaluated and discussed.

\section{OUTLINE OF SHAKING TABLE TEST}

\subsection{Building models}

The test building models considered in this study are shown in Fig. 2. The two single-storey models shown in Fig. 2a and b are referred to as Models $1 \mathrm{~A}$ and $1 \mathrm{~B}$, respectively, and the single two-storey building model shown in Fig. 2c is referred to as Model 2. The floor mass of both Models $1 \mathrm{~A}$ and $1 \mathrm{~B}$ are $2.51 \mathrm{~kg}$, while the floor mass of Model 2 at levels 1 and 2 are $3.24 \mathrm{~kg}$ and $2.51 \mathrm{~kg}$, respectively. The columns of each building model are aluminium plates of thicknesses $1.5 \mathrm{~mm}$ for Models $1 \mathrm{~A}$ and 2, and $2.0 \mathrm{~mm}$ for Model 1B. To adjust the structural damping of each model, viscoelastic material is installed on each storey, with a rigid support column free to execute rocking movements.

The natural period and the damping ratio of single-storey models are obtained from the free vibration test. The natural period and the damping ratio of Model $1 \mathrm{~A}$ are $0.195 \mathrm{~s}$ and 0.096, respectively, while those of Model 1B are $0.144 \mathrm{~s}$ and 0.035, respectively. The natural period and the damping ratio of each mode of Model 2 are obtained from the elastic vibration test without pounding. The natural period is $0.400 \mathrm{~s}$ for the first mode and $0.141 \mathrm{~s}$ for the second mode. The damping ratio, based on the half-power method, is 0.055 for the first mode and 0.041 for the second mode.

\subsection{Test parameters}

Figure 3 shows the arrangement of the pounding test. Because of size limitations during the shaking table test, the two building models were set in parallel. On the level 1 of each model, the pounding arm element was installed to facilitate collisions of two building models during the test. Therefore, the pounding in this test was asymmetric pounding, which caused a 


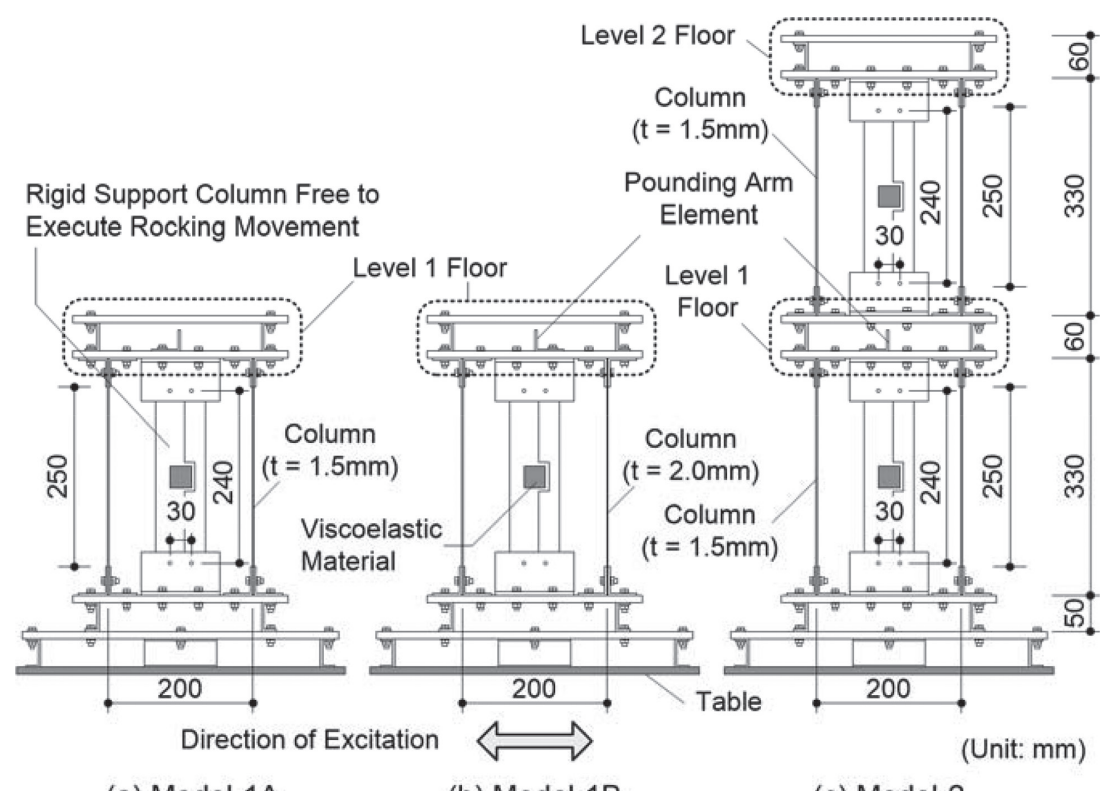

(a) Model-1A

(b) Model-1B

(c) Model-2

Figure 2: Building models.

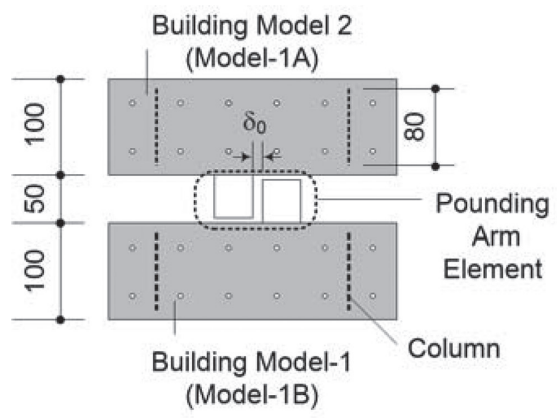

(a) Test 1

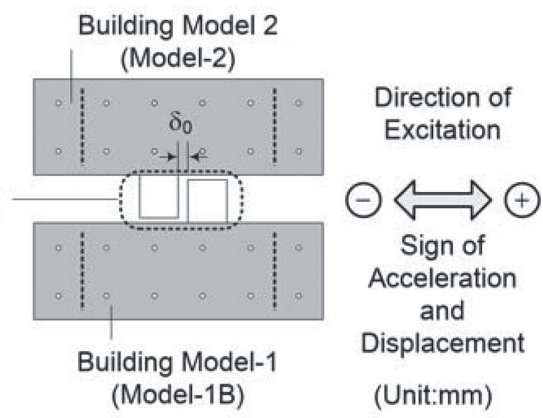

(b) Test 2

Figure 3: Arrangement of pounding test.

torsional response in both models. To minimise the torsional response, the width of the columns in each storey was determined as $80 \mathrm{~mm}$ and the distance between two columns as $200 \mathrm{~mm}$ to provide a large storey torsional stiffness.

In the tests, the following parameters were studied: a) the pairing of the two building models, and b) the size of the gap $\delta_{0}$.

a) Pairing of the two building models. In Test 1, the seismic pounding of the two singlestorey building models (Models 1A and 1B) shown in Fig. 3a were investigated. In Test 2, the seismic pounding of a single-storey building model (Model 1B) and a two-storey building model (Model 2) were investigated, as shown in Fig. 3b.

b) The size of the gap $\delta_{0}$. The gap between the two building models was considered as shown in Fig. 3. The size of the gap $\delta_{0}$ was set to $0,5 \mathrm{~mm}, 10 \mathrm{~mm}$, and infinite (without pounding). 


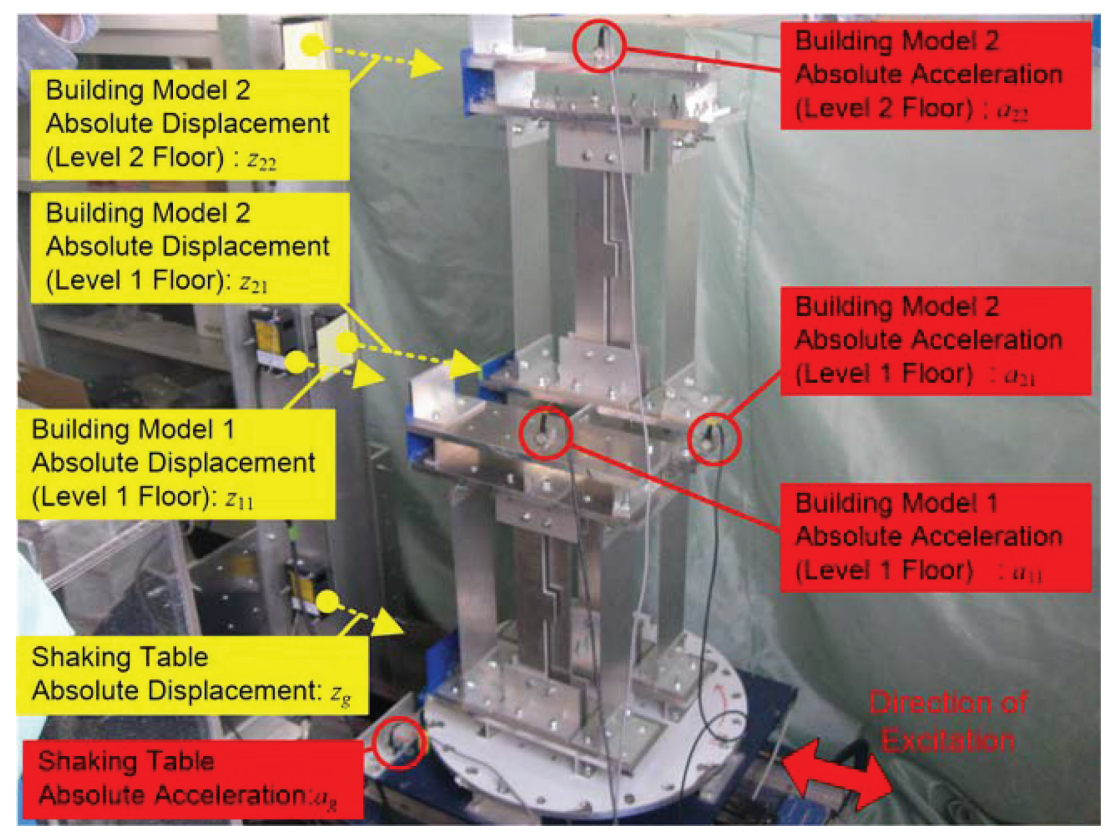

Figure 4: Experimental set-up.

\subsection{Experimental setup and seismic input}

Figure 4 shows the experimental set-up, where the absolute accelerations of all floors (absolute acceleration at level 1 of building Model 1, $a_{11}$, and at level 1 and 2 of building Model 2, $a_{21}$ and $a_{22}$, respectively) and at the shaking table, $a_{g}$, are shown as measured by the accelerometers. The absolute displacement of all floors (absolute displacement at level 1 of building Model $1, z_{11}$, and at levels 1 and 2 of building Model 2, $z_{21}$ and $z_{22}$, respectively) and at the shaking table, $z_{g}$, were measured by laser sensors. The sampling interval is $0.001 \mathrm{~s}$. The relative displacement of all floors, $y_{11}, y_{21}$, and $y_{22}$ are calculated from

$$
y_{11}(t)=z_{11}(t)-z_{g}(t), y_{21}(t)=z_{21}(t)-z_{g}(t), y_{22}(t)=z_{22}(t)-z_{g}(t)
$$

Figure 5 shows the pseudo-velocity spectrum and input energy spectrum proposed by Akiyama [14]. As shown in this figure, the El Centro 1940 North-South (NS) ground motion record (ELC), the Tohoku University 1978 NS ground motion record (TOH), and the Japan Meteorological Agency Kobe 1995 NS ground motion record (JKB) were used for the shaking table test. In this test, the peak acceleration was scaled to $40 \%$ of the acceleration due to gravity, and the time interval of three ground motions were scaled by half for the following reasons: i) to simulate the seismic pounding of both low-rise buildings (Test 1) and a low-rise to a mid-rise building (Test 2); ii) to adjust the maximum movement of the shaking table within the allowable limit; and iii) to adjust the response of the building model within the elastic range. 


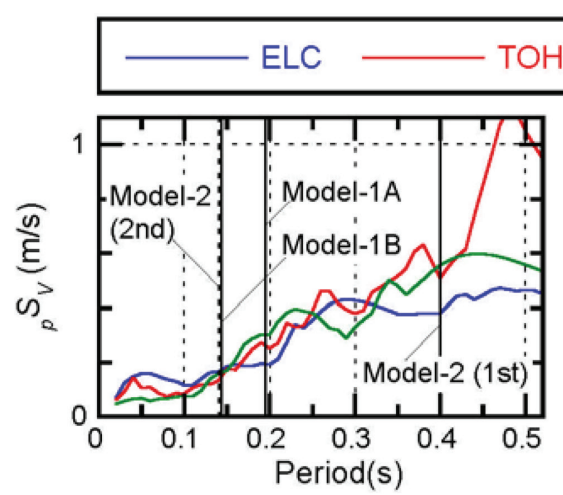

(a) Pseudo-Velocity Spectrum (Damping ratio: 0.05)

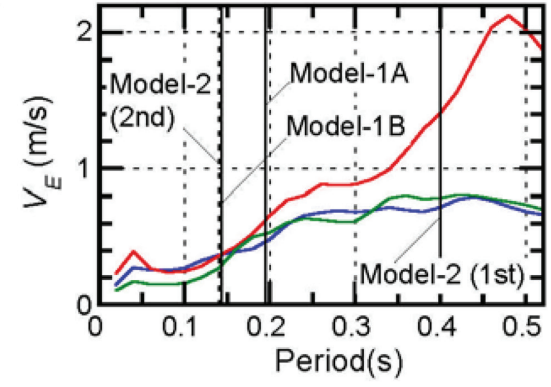

(b) Input Energy Spectrum (Damping ratio: 0.10 )

Figure 5: Response spectrum of seismic input.
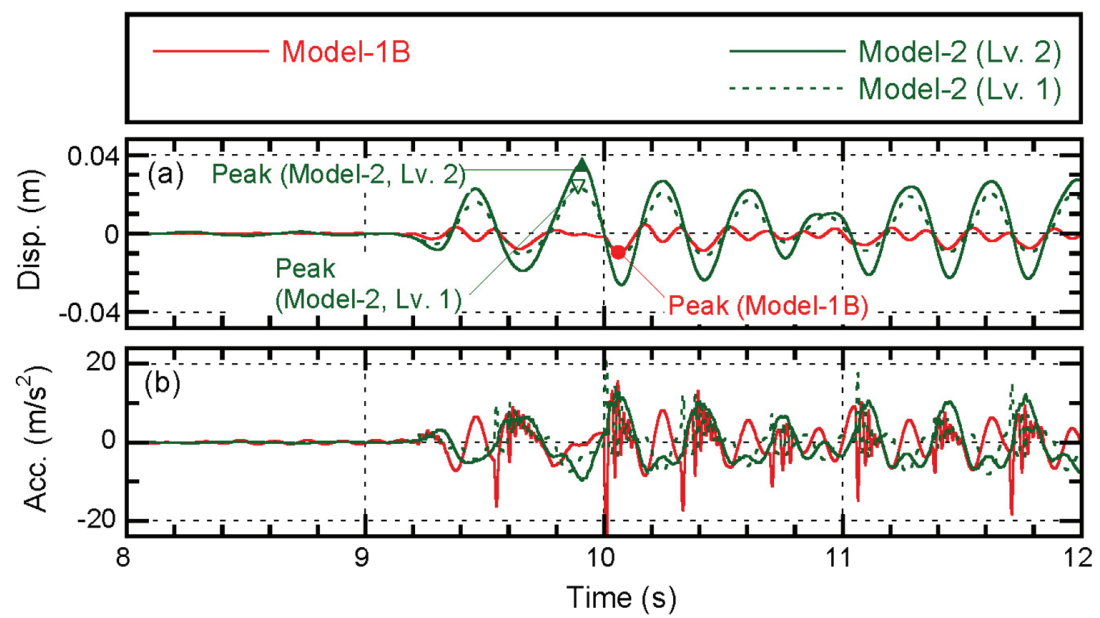

Figure 6: Time-history of Test 2 (seismic input: JKB, $\delta_{0}=0$ ). (a) Relative displacement at the floor, and (b) absolute acceleration at the floor.

\section{TEST RESULTS}

\subsection{Time-history of seismic pounding}

Figure 6 shows the time-history of Test 2 (seismic input: JKB, $\delta_{0}=0$ ), where the relative displacement (Model 1B: $y_{11}$, Model 2: $y_{21}$ and $y_{22}$ ) and the absolute acceleration (Model 1B: $a_{11}$, Model 2: $a_{21}$ and $a_{22}$ ) are displayed.

Sharp spikes in the acceleration response are evident when the relative displacement of Model 1B is almost equal to that of level 1 in Model 2. A sharp spike in the acceleration response is considered here as a 'collision'.

\subsection{Normalised inter-storey drift}

Figures 7 and 8 show the normalised inter-storey drift for each case, defined as the ratio of the peak inter-storey drift with pounding, divided by that without pounding $\left(\delta_{0}=\right.$ infinite). 


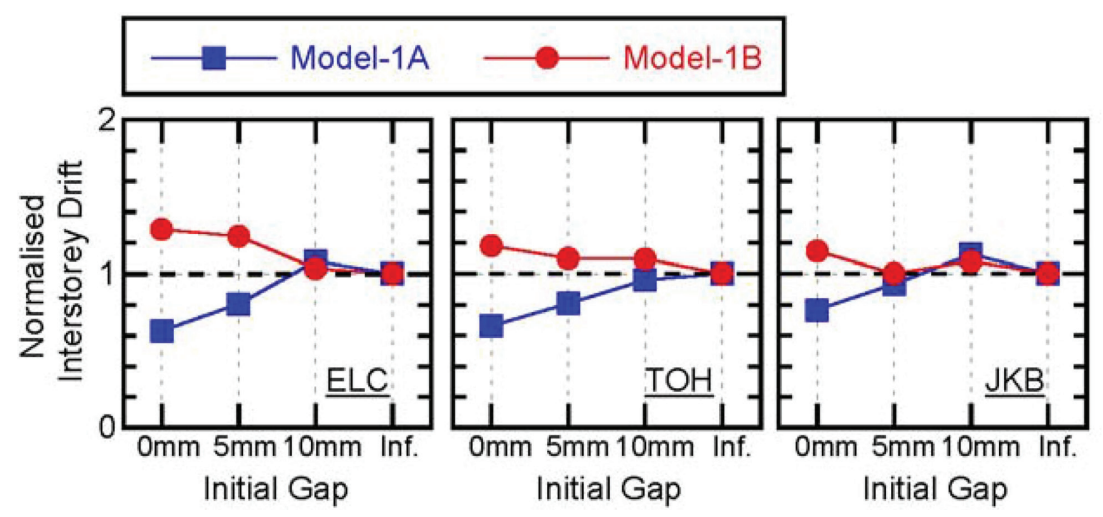

Figure 7: Normalised inter-storey drift (Test 1).

It is observed in Test 1 from Fig. 7 that the normalised drift of Model $1 \mathrm{~A}$ is smaller than 1 in most cases; the normalised inter-storey drift is smaller as the gap $\delta_{0}$ is smaller. On the contrary, the normalised drift of Model $1 \mathrm{~B}$ is larger than 1 in most cases. This observation indicates that, in the case of the pounding of low-rise buildings, the peak displacement of the shorter period building increases, while that of the longer period building decreases.

In Test 2, it is observed from Fig. 8 that the normalised drift of Model 1B is larger than 1 in all cases; the normalised inter-storey drift is larger as the gap $\delta_{0}$ is smaller. This tendency is more significant when the seismic input is either TOH or JKB rather than ELC. However, the trend of Model 2 depends on each storey: in the second storey, the normalised drift is larger than 1 in most cases, while it is smaller than 1 in the first storey in all cases. This observation indicates that, in the case of the pounding of a low-rise building to a mid-rise building, the peak storey drift of the low-rise building increases. In the mid-rise building, the peak storey drift of the upper storey increases, while that of the lower storey decreases.

\section{CHANGE IN THE KINETIC ENERGY DURING THE COLLISION}

The discussion that follows focuses on the change in the kinetic energy of each structure during the collision: the increment of kinetic energy during each collision is evaluated.

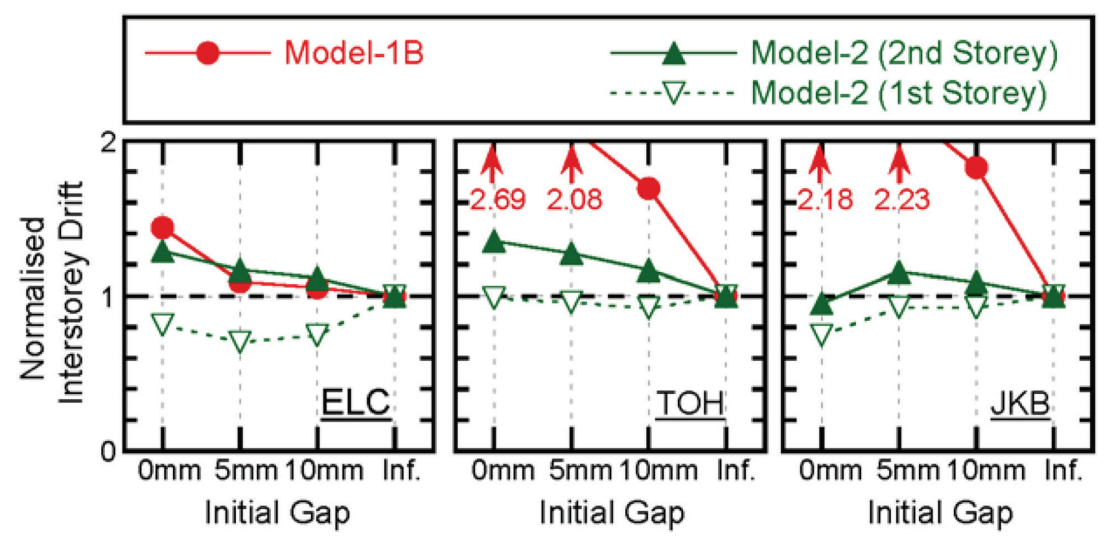

Figure 8: Normalised inter-storey drift (Test 2). 
In this study, the kinetic energy of building models 1 and 2 at time $t, W_{K 1}(t)$ and $W_{K 2}(t)$, respectively, are calculated from

$$
W_{K 1}(t)=\frac{1}{2} m_{11}\left\{\dot{y}_{11}(t)\right\}^{2}
$$

and

$$
W_{K 2}(t)=\left\{\begin{array}{ll}
\frac{1}{2} m_{21}\left\{\dot{y}_{21}(t)\right\}^{2} & \text { for Test } 1 \\
\frac{1}{2} \sum_{j=1}^{2} m_{2 j}\left\{\dot{y}_{2 j}(t)\right\}^{2} & \text { for Test } 2
\end{array} .\right.
$$

Here, $m_{11}$ is the floor mass of building Model 1 , while $m_{21}$ and $m_{22}$ are the floor masses of building Model 2 at levels 1 and 2, respectively.

\subsection{Definition of collision time}

The relative displacement between the building model $\delta(t)$, is defined as

$$
\delta(t)=y_{21}(t)-y_{11}(t) .
$$

Figure 9 shows the definition of the collision time in this study. The collision time of the $i$ th pounding, $\Delta_{i} t_{c}$, is defined as

$$
\Delta_{i} t_{c}={ }_{i} t_{c 1}-{ }_{i} t_{c 0} .
$$

Here, ${ }_{i} t_{c 0}$ and ${ }_{i} t_{c 1}$ are the beginning and ending time of the collision during the $i$ th pounding, respectively, and are defined as:

$$
\text { beginning time of collision }{ }_{i} t_{c 0}: \delta(t)=\delta_{0} \text { and } \dot{\delta}(t) \geq 0
$$

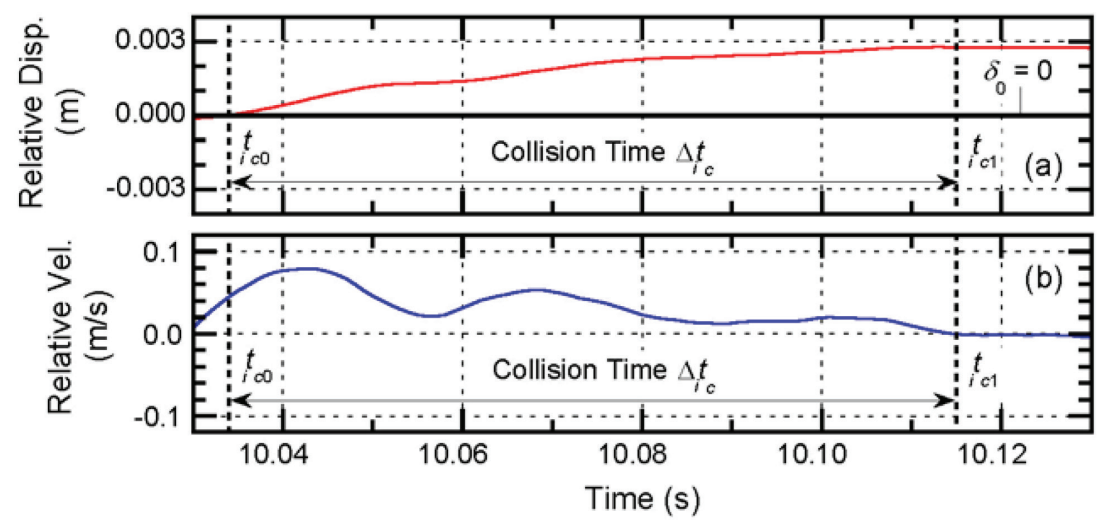

Figure 9: Definition of collision time in the case of an initial gap $\delta_{0}=0$. (a) Relative displacement between the building model $\delta(t)$, and (b) relative velocity between building model $\dot{\delta}(t)$. Note that the beginning time of collision $t_{c 0}$ depends on $\delta_{0}$, while the ending time $t_{c 1}$ is independent of $\delta_{0}$. 
and

$$
\text { ending time of collision }{ }_{i} t_{c 1}: \delta(t) \geq \delta_{0} \text { and } \dot{\delta}(t)=0 \text {. }
$$

Note that this definition of the collision time is consistent with 'the approach period of the collision' in [9]. The increment of kinetic energy during a collision of building Models 1 and 2 of the $i$ th pounding, $\Delta_{i} W_{K 1}$ and $\Delta_{i} W_{K 2}$, respectively, are then calculated from

$$
\Delta_{i} W_{K 1}=W_{K 1}\left({ }_{i} t_{c 1}\right)-W_{K 1}\left({ }_{i} t_{c 0}\right), \Delta_{i} W_{K 2}=W_{K 2}\left({ }_{i} t_{c 1}\right)-W_{K 2}\left({ }_{i} t_{c 0}\right) .
$$

\subsection{Sum of the increment of kinetic energy and the variation of maximum kinetic energy}

Figures 10 and 11 show the sum of the increment of kinetic energy of building models, $\Sigma\left(\Delta_{i} W_{K 1}\right)$ and $\Sigma\left(\Delta_{i} W_{K 2}\right)$, for Tests 1 and 2 , respectively.

In Test 1 (Fig. 10), the sum of the increment of kinetic energy of both Models $1 \mathrm{~A}$ and $1 \mathrm{~B}$ are negative except Model 1B for the case of a TOH seismic input, and the initial gap $\delta_{0}$ is 0 . In general, both building models lose kinetic energy as a result of the collisions. These trends are more significant in the case of a smaller initial gap $\delta_{0}$. In Test 2 (Fig. 11), the sum of the increment of kinetic energy of Model 1B is positive, while that of Model 2 is negative in all cases. These trends are more significant in the case of a smaller initial gap $\delta_{0}$.

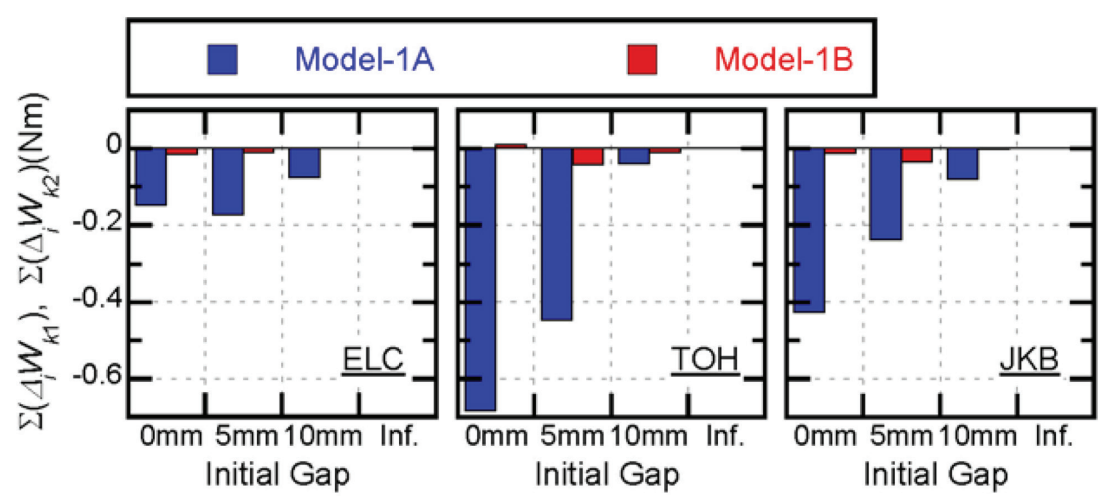

Figure 10: Sum of the increment of kinetic energy (Test 1).

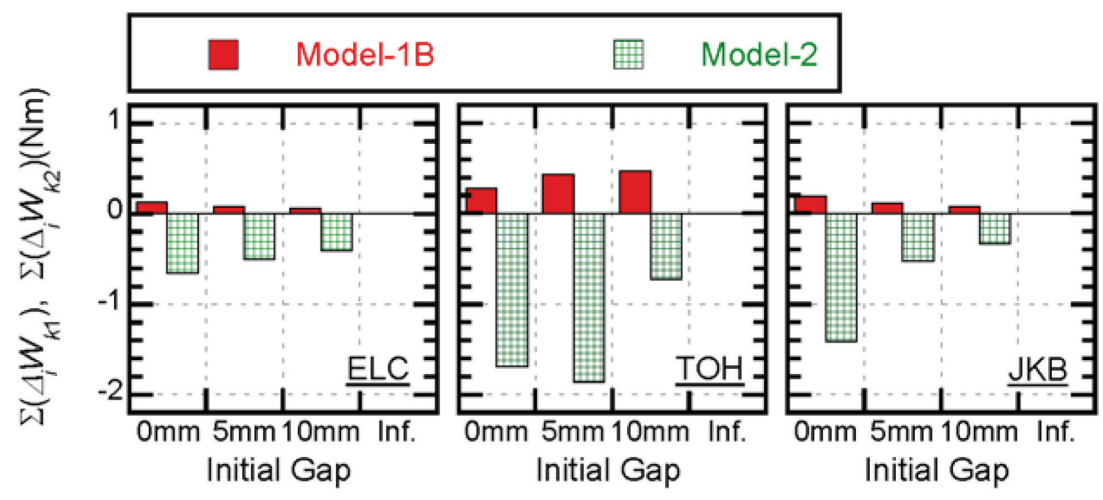

Figure 11: Sum of the increment of kinetic energy (Test 2). 


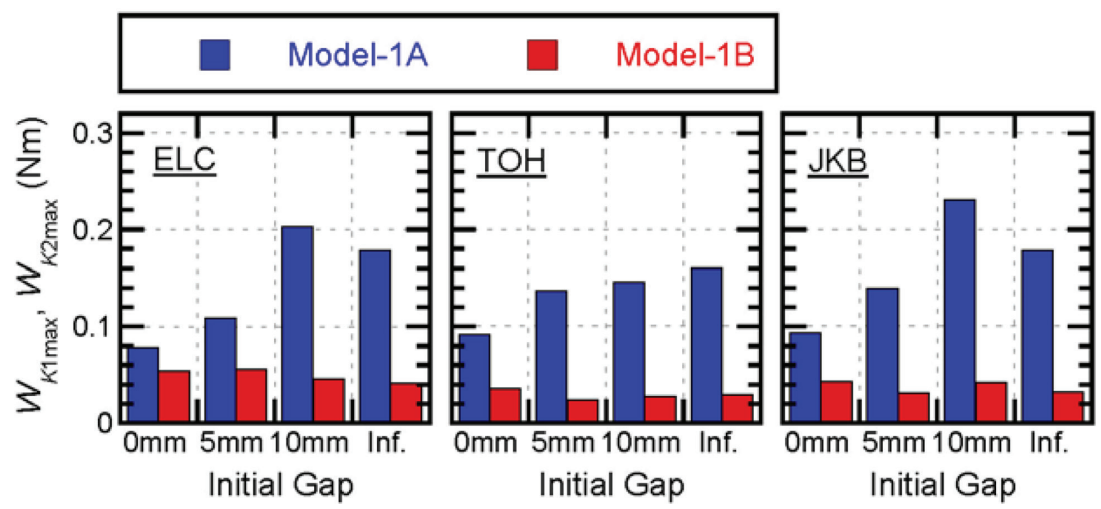

Figure 12: Maximum kinetic energy (Test 1).

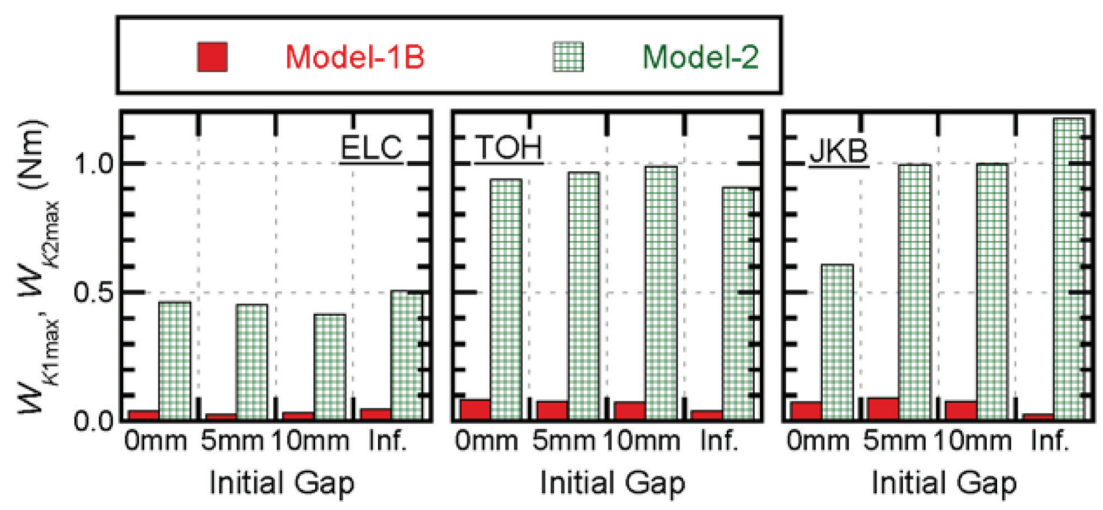

Figure 13: Maximum kinetic energy (Test 2).

Figures 12 and 13 show the maximum kinetic energy of the building models, $W_{K 1 \max }$ and $W_{K 2 \max }$, for tests 1 and 2, respectively.

In Test 1 (Fig. 12), the maximum kinetic energy of Model 1A is larger than that of Model 1B. This figure also shows that, in general, the maximum kinetic energy of Model 1A decreases while that of Model 1B increases due to the collision. In Test 2 shown in Fig. 13, the maximum kinetic energy of Model 2 is larger than that of Model 1B. The trend of the variation of the maximum kinetic energy due to the collisions of each model depends on the seismic input and initial gap $\delta_{0}$.

From the discussions on the change of the kinetic energy of each structure during the collision (shown in Figs 10 and 11), and the results of the tests shown in the previous section, it is found that the building model with more kinetic energy loses more energy due to collisions, and the unfavourable effect of seismic pounding to the response is less significant. On the contrary, the building model with lesser kinetic energy may gain more energy from the collisions, and the unfavourable effect of seismic pounding to the response is predominant.

\section{CONCLUSIONS}

In this study, shaking table tests of building models were carried out to investigate the seismic pounding of (1) low-rise buildings, and (2) a low-rise to a mid-rise building. Based on the test 
results, the increment of kinetic energy during the collision is evaluated and discussed. Although the test cases shown here are limited, the main findings of this study are as follows:

1. In the case of the pounding of low-rise buildings, the peak displacement of the stiffer building increases, while that of the more flexible building decreases.

2. In the case of the pounding of a low-rise building to a mid-rise building, the peak interstorey drift of the low-rise building increases. In the mid-rise building, the peak interstorey drift of the upper storey increases, while that of the lower storey decreases.

3. The sum of the increment of kinetic energy during the collision was larger as the gap between the buildings was smaller. A significant loss in kinetic energy was evident in those structures for which the maximum kinetic energy is larger.

4. The building model with more kinetic energy loses more energy from the collisions, and the unfavourable effect of seismic pounding to the response is less significant. On the contrary, the building model with lesser kinetic energy may gain more energy from the collisions, and the unfavourable effect of seismic pounding to the response is predominant.

It should be noted that the maximum kinetic energy of buildings without seismic pounding can be easily estimated from the response spectrum. Therefore, buildings more susceptible to the dangers of seismic pounding may be detected from the response spectrum. This point will be taken up in the next phase of this study.

\section{REFERENCES}

[1] Bertero, V.V., Implications of observed pounding of buildings on seismic code regulations. Proceeding of the Eleventh World Conference on Earthquake Engineering, Elsevier: paper no. 2102, 1996.

[2] Kasai, K., Jeng, V., Patel, P.C. \& Munshi, J.A., Seismic pounding effects - survey and analysis. Proceeding of the Tenth World Conferenec on Earthquake Engineering, Balkerma: pp. 3893-3898, 1992.

[3] Kasai, K., Jagiasi, A.R. \& Maison, B.F., Survey and analysis of building pounding during 1989 Loma Prieta Earthquake. Proceeding of the Eleventh World Conference on Earthquake Engineering, Elsevier: paper no. 2103, 1996.

[4] Cole, G.L., Dhakel, R.P. \& Turner, F.M., Building pounding damage observed in the 2011 Christchurch earthquake. Earthquake Engineerings and Structural Dynamics, 41, pp. 893-913, 2012. https://doi.org/10.1002/eqe.1164

[5] Maison, B.F. \& Kasai, K., Dynamics of pounding when two buildings collide. Earthquake Engineerings and Structural Dynamics, 21, pp. 771-786, 1992. https://doi.org/10.1002/eqe.4290210903

[6] Anagnostopoulos, S.A., Pounding of buildings in series during earthquakes. Earthquake Engineerings and Structural Dynamics, 16, pp. 443-456, 1988. https://doi.org/10.1002/eqe.4290160311

[7] Anagnostopoulos, S.A. \& Spiliopoulos, K.V., An investigation of earthquake induced pounding between adjacent buildings. Earthquake Engineerings and Structural Dynamics, 21, pp. 289-302, 1992.

https://doi.org/10.1002/eqe.4290210402 
[8] Wada, A., Shinozaki, Y. \& Nakamura, N., Collapse of building with expansion joints through collision caused by earthquake motion. Proceeding of the Eighth World Conference on Earthquake Engineering, 4, pp. 855-862, 1984.

[9] Jankowski, R., Non-linear viscoelastic modelling of earthquake-induced structural pounding. Earthquake Engineerings and Structural Dynamics, 34, pp. 595-611, 2005. https://doi.org/10.1002/eqe.434

[10] Jankowski, R., Earthquake-induced pounding between equal height buildings with substantially different dynamic properties. Engineering Structures, 30, pp. 2818-2829, 2008.

https://doi.org/10.1016/j.engstruct.2008.03.006

[11] Papadrakakis, M. \& Mouzakis, H.P., Earthquake simulator testing of pounding between adjacent buildings. Earthquake Engineerings and Structural Dynamics, 24, pp. 811834, 1995.

https://doi.org/10.1002/eqe.4290240604

[12] Chau, K.T., Wei, X.X., Guo, X. \& Shen, C.Y., Experimental and theoretical simulations of seismic poundings between two adjacent structures. Earthquake Engineerings and Structural Dynamics, 32, pp. 537-554, 2003.

https://doi.org/10.1002/eqe.231

[13] Jankowski, R., Experimental study on earthquake-induced pounding between structural elements made of different building materials. Earthquake Engineerings and Structural Dynamics, 39, pp. 343-354, 2010.

[14] Akiyama, H., Earthquake-resistant limit-state design for buildings, University of Tokyo Press: Tokyo, 1985. 